\title{
RECORDANDO A JAVIER GARCÍA-BELLIDO EN UN MOMENTO DE INFLEXIÓN
}

\section{Fernando Roch Peña}

Catedrático de Urbanismo, Departamento de Urbanismo y Ordenación del Territorio Escuela Técnica de Arquitectura de Madrid, Universidad Politécnica de Madrid Madrid, España

Remisión Artículo: 16-1-2007

Palabras Claves: COPLACO, Servicio Técnico de Urbanismo de la Diputación Provincial de Madrid, Gabinete de Estudios, Planeamiento Metropolitano.

Ya ha pasado el tiempo de la dolorosa sorpresa seguida de los resúmenes apresurados que querían evocar al amigo y al colega como tratando de contradecir lo inevitable, y es tiempo para la memoria más pausada, esa que hemos construido de forma colectiva y que, por compartida, se mantiene viva entre todos, y en la que Javier ocupa un lugar tan singular. A partir de ahora, se irán sucediendo las valoraciones críticas de la extensa obra que nos ha dejado. Extensa y variada como se ha señalado tantas veces en los últimos meses, porque si algo se puso de manifiesto en los diferentes homenajes que se le han rendido es la extraordinaria multiplicidad de disciplinas que han coincidido en lamentar su pérdida y valorar sus aportaciones. Nadie como él ha personificado esa cualidad del urbanismo que lo convierte en una disciplina de síntesis, seguramente porque pocos han hecho un esfuerzo semejante para construir su cuerpo doctrinal.

Pero no quisiera entrar ahora en cuestiones de tanta enjundia que ya irán saliendo a medida que se dé continuidad a sus trabajos o que se realicen proyectos de investigación similares, sino recordar un momento particular -entre 1981 y 1983 - en que colaboramos más estrechamente, porque me parece que es una manera de recordarlo en la proximidad y porque, todo hay que decirlo, fue un momento en el que algunos, él primero, pusimos muchas ilusiones en lo que hacíamos, y porque se estaban produciendo cambios irrepetibles a nuestro alrededor que iban a marcar decisivamente el curso posterior del desarrollo urbano español, el papel de los urbanistas en las burocracias del nuevo orden, las nuevas modalidades de gobierno del territorio y el lugar ciertamente marginal que el sistema reservaría a la crítica y al estudio de los fenómenos urbanos. Demasiadas cosas que quizás exijan esbozar, aunque sea con unas rápidas pinceladas, la "pequeña historia" de ese momento en el que Javier García-Bellido puso en juego toda su personalidad y su empeño para dibujar lo que podría haber sido un camino alternativo.

Ya antes yo había coincidido con Javier, a principios de 1972, en el Gabinete de Estudios de la Dirección General de Urbanismo, donde nos reunimos un nutrido grupo de jóvenes urbanistas bajo la dirección técnica de F. Fernández-Longoria —nos instalamos en la que había sido la vivienda de José Luís Arrese, en un ático del Ministerio de la Vivienda que él había dirigido desde su fundación- para analizar lo que había dado de sí la Ley del Suelo de 1956 después de 15 años de aplicación. Se trataba más de valorar su eficacia como instrumento de producción de ciudad que otra cosa, estudiando el desarrollo de los Planes Generales de las ciudades más importantes del país, y de proponer las medidas que en lo sucesivo fueran 
necesarias para corregir los desajustes y acomodar las regulaciones urbanísticas a la nueva realidad española. Un Libro Blanco y la Ley de 1975 (texto refundido del 76) fueron los resultados de aquella experiencia en colaboración con la Dirección General de Urbanismo del todavía Ministerio de la Vivienda. Javier estuvo sólo el primer año, hasta 1973 en que se trasladó a Londres para hacer un Master en planificación urbana en el Postgraduate Planning School de la Architectural Association School of Architecture, del que volvió en 1975. Todavía a tiempo para colaborar en la redacción del desarrollo reglamentario de la Ley, que se prolongó hasta 1980. Fue en todo caso una ocasión única para analizar críticamente el crecimiento de unas 60 ciudades españolas: las capitales de provincia y las de más de 50.000 habitantes. Para entonces, la cultura de la planificación flexible, que se realizaba en Gran Bretaña o en Francia, había desplazado el centro de interés hacia los aspectos estructurales del modelo urbano -era fundamental distinguir lo que permanecía, lo estructural, y lo que admitía tratamientos flexibles, sobre los que operaba el inmobiliario-, y eso desbordaba ampliamente las limitaciones de la "reserva urbana" y del planeamiento de Extensión de la Ley del 56. Revisar conceptos e instrumentos de planificación y desarrollo urbano se convertía, por tanto, en una exigencia inaplazable. Pero ya se anunciaban otras cuestiones que empujaban no sólo a revisar metodologías de planeamiento o modelos de desarrollo, sino la propia disciplina, su cultura básica y sus dominios. De hecho estábamos en las vísperas de un cambio radical que terminaría por transformar el sentido mismo y las funciones básicas de nuestras ciudades. Preocupados por los problemas de producción de la ciudad — los relacionados con la máquina de crecimiento y el sistema inmobiliario-y por algunos aspectos generales de la reproducción -el despliegue, aunque fuera restringido, del Bienestar que en España estaba muy atrasadoapenas habíamos reparado que las metrópolis industriales —eficientes y altamente productivas, con sus miserias y sus grandezas- que nos habían servido de modelo tenían los días contados. De esta forma, y sin haber empezado realmente a consolidar un "urbanismo industrial moderno" nos veíamos empujados a pasar a la etapa siguiente que, para hacerlo más difícil, icarecía de modelos!

A finales de los 70 casi todos nosotros habíamos estudiado en el extranjero y disponíamos de experiencias y conocimientos que prometían mejorar notablemente la práctica urbanística española a poco que disfrutáramos de oportunidades, bien es verdad que con visiones dispares y compromisos diferentes, pero todos nos sentíamos implicados en cambiar las cosas. El problema es que el modelo principal se agotaba y las cosas iban a cambiar sin nuestro concurso poniendo a prueba nuestra capacidad para adelantar un futuro que se llenaba de incertidumbres. Y por si fuera poco, la situación se complicaba aún más porque los profundos cambios del régimen económico que se nos echaban encima coincidieron con una nueva situación política, que ponía el gobierno del territorio en manos nuevas y democráticas, pero con escasa experiencia. Fue realmente un momento excepcional cuya evolución inmediata apenas cinco años- marcó definitivamente el curso del urbanismo español hasta desembocar en la lamentable situación actual. Y fue precisamente entonces cuando vuelvo a coincidir con Javier para llevar adelante, junto con un grupo de colegas, una empresa que aún considero la más estimulante de mi experiencia como planificador urbano.

Hace unas semanas, en una columna publicada en un periódico nacional se recriminaba a los profesionales del urbanismo - a todos sin distinciones- por lo que se entendía como complicidad ante el proceso de degradación que había alcanzado la cultura urbanística, y el silencio culpable que manteníamos ante la corrupción generalizada que preside el desarrollo 
urbano actual en España. En un momento de su discurso se preguntaba dónde estaban los urbanistas comprometidos, de izquierdas, que en los años 80 habían luchado por una (verdadera) ciudad para (verdaderos) ciudadanos, pero creo que habría que incluir en esa responsabilidad a los propios ciudadanos que deberían haber defendido su condición y su naturaleza por encima de sus intereses monetarios y, también y sobre todo, a los medios de comunicación que vienen negándose sistemáticamente a publicar las denuncias que con frecuencia les hemos hecho llegar ${ }^{1}$. En todo caso, hay que reconocer lo pertinente de la pregunta y el tino con que la periodista sitúa el momento en que todo parecía que podría haber sido diferente, porque fue precisamente a principios de los 80 cuando unos pocos iniciamos, con Javier a la cabeza y como sujeto contratante, en un lugar tan insólito como la vieja Diputación Provincial de Madrid, que acababa de ganar el PSOE como resultado de las primeras elecciones locales de la democracia, un ensayo que carecía de antecedentes y que podría haber inspirado una cultura urbanística bien diferente.

La distancia ha borrado algunos detalles pero resulta inolvidable el momento de zozobra que nos regaló la asonada del $23 \mathrm{~F}$ y que nos acompañó en los preliminares del proyecto. Fue, en efecto, en febrero de 1981 cuando se concretó el encargo de organizar un Servicio Técnico de Urbanismo en la Diputación, algo que nunca había existido, para tratar de atender desde una perspectiva nueva a las necesidades de los municipios de la región. Se trataba claramente de iniciar un nuevo camino en el urbanismo madrileño que diera la réplica a COPLACO que, como agencia estatal, se encontraba aún en manos de UCD y que había dirigido la fase de desarrollo que agonizaba. Todavía recuerdo la tensión que vivimos la mañana del 24 de febrero en la sala de visitas de la presidencia de la Diputación mientras esperábamos ser recibidos - la cita se había programado días antes para presentar al equipo-, escuchando por la radio las últimas noticias de aquel episodio ominoso.

Era una situación inédita, ya que las elecciones locales acababan de poner en manos de la izquierda el gobierno del territorio, empezando por el Ayuntamiento de Madrid, pero el organismo que conservaba las competencias reguladoras seguía siendo aquella agencia estatal —una especie de Prefectura Metropolitana a la francesa - que había sido creada en 1963 para dirigir el despliegue del Área Metropolitana madrileña, según un ambiguo modelo que aceptaba la industrialización a regañadientes. Bien es verdad que se trataba, casi veinte años después de su creación, de un organismo muy evolucionado en el que se habían formado muchos de los urbanistas que iban a trabajar en las décadas siguientes, y cuya cultura se había ido enriqueciendo con aportaciones de muchas latitudes, al tiempo que derivaba hacia preocupaciones más sociales sin renunciar, desde luego, al desarrollismo propio de aquellas décadas $^{2}$. Dentro de aquel nuevo dispositivo que trataba de proporcionar un escenario

\footnotetext{
${ }^{1}$ Soledad Gallego-Díaz, Miserables Urbanistas, El País, 8 de diciembre de 2006. Muchos somos los que hemos enviado sin éxito textos a la prensa, al País también claro está, denunciando el problema en sus muchas dimensiones, pero la ley del silencio se ha impuesto, incluso cuando han peligrado las instituciones democráticas, como en el minigolpe de Estado de la Comunidad de Madrid de 2003, cuya naturaleza inmobiliaria era evidente. Los medios de comunicación han sido en general los verdaderos difusores de la cultura urbanística neoliberal -mantener que el precio de la vivienda deriva del precio del suelo es el origen de todo este desastre-, y los cómplices del estado de deterioro que ha alcanzado el problema urbanístico, junto con el aparato municipal e inmobiliario-financiero del PP (también los de otros partidos aunque con una implicación bastante menor).

${ }^{2}$ En ese etapa final se habían redactado los PAI que constituían un intento de encajar la participación popular en las decisiones de gobierno del territorio madrileño que no tenía precedentes y que desgraciadamente tampoco tuvo continuación, porque se apoyaba en el movimiento asociativo vecinal que había nacido durante la dictadura y que también fue sacrificado irresponsablemente poco después.
} 
urbanístico para la región más acorde con la realidad política, jugaba un papel especial el municipio central que estaba redactando el Plan General que se aprobaría en 1985, y que por primera vez en veinte años abandonaba el formato de un plan Metropolitano, ya que carecía de competencias para ello. El Consejo de Municipios —un organismo de naturaleza política que intentaba concertar cuestiones territoriales - intentó precisamente cubrir esa deficiencia sentando en la misma mesa a los responsables de los municipios metropolitanos en materia urbanística, la mayoría, si no todos, gobernados por la izquierda. La idea era reconstruir la eficiencia de gobierno - una especie de Plan Director metropolitano- a través de la concertación del planeamiento general municipal de todos sus componentes, que sí era de su competencia. Javier, como director del Servicio de Urbanismo de Diputación fue uno de los miembros del equipo técnico que, por cierto, se reunía en nuestras oficinas. El resultado de aquel esfuerzo se recogió en un libro, pero en realidad se trataba de un proyecto imposible ${ }^{3}$.

La tercera pata del dispositivo, mucho más modesta -apenas superábamos la docena de personas-, pero mucho mejor centrada en su escenario, era ese Servicio de Urbanismo que ofrecía la vieja Diputación con Javier García-Bellido como director y bajo la responsabilidad política de César Cimadevilla, que sintonizó perfectamente desde el principio con el equipo y que se convirtió en nuestro mejor aliado. Se trataba en todo caso de un organismo menos político, o en otro orden político si se prefiere, y mucho más cultural, mucho más enfocado al entorno del sistema y sobre un ámbito en el que era posible ensayar un urbanismo diferente poniendo como objetivo central explorar lo ciudadano, armonizar el crecimiento y sus formas con la naturaleza del territorio y desarrollar un urbanismo democrático mediante la participación. El área de trabajo cubría toda la provincia — la actual Comunidad de Madrid-, aunque en realidad, y salvo casos excepcionales, nuestra tarea se centraba sobre todo en ese gran entorno provincial que quedaba más allá de la delimitación del Área Metropolitana, y que ahora es el teatro de tantos escándalos. También era el universo político más plural, con alrededor de 170 municipios de todos los colores. Puede decirse, pues, que en aquel momento en Madrid había tres equipos significativos trabajando, aparte del de la Dirección General de Urbanismo estatal: el de COPLACO que había perdido protagonismo pero no efectivos y que seguía la línea tradicional de la máquina de crecimiento inmobiliaria, el del Ayuntamiento de Madrid que redactaba el Plan de 1985 —numeroso, cualificado y bien retribuido- inspirado por la cultura de la Austeridad, y nosotros. Apenas duró dos años la aventura pero en ese tiempo se desplegó una actividad insólita y creo que lo pasamos muy bien.

Bajo el impulso de Javier, por primera vez desde la administración del territorio, y sin apenas competencias, se creó un grupo verdaderamente heterodoxo que inició un trabajo de planeamiento que abrió nuevas perspectivas al gobierno del territorio, muy lejos de las rutinas burocráticas y de las líneas desarrollistas tradicionales. En ese sentido, aquel grupo fue un semillero de funcionarios muy atípicos, y Javier el más atípico de todos. Puede que el hecho de no trabajar todo el tiempo en el mismo ojo del huracán de los grandes intereses inmobiliarios que entonces se jugaban todavía en el recinto metropolitano ayudara algo, pero ya se manifestaban los primeros y extensivos contagios que hoy han llevado al fenómeno de corrupción que conocemos. En pocas palabras, el proyecto que dirigió Javier García-Bellido

${ }^{3}$ García-Bellido, J., F. Longoria, F., Leira, E., Ruiz de Elvira, J. Planeamiento Metropolitano. Criterios y Objetivos (1982), Diputación Provincial de Madrid. Cabe recordar que los sucesivos Planes Directores o Directrices Territoriales que ya desde la propia $\mathrm{CM}$ se han ido redactando desde entonces tampoco han logrado convertirse en un instrumento real de gobierno del territorio. 
reproducía la idea de un observatorio urbano un poco a la "Geddes" y de una asistencia "de cabecera" a los ayuntamientos, al tiempo que introducía avant la lettre, en las prácticas de planeamiento, las preocupaciones ecologistas y la cultura democrática que tanto nos hubieran ayudado ahora. Se hizo un urbanismo de entorno que reconocía la importancia de lo local, de su alteridad y de su capacidad de resistencia, es decir, de la presencia de modos de producción, de formas de vida y de culturas del territorio que diferían de las que imponía el capitalismo dominante y a partir de las cuales se podía construir también una evolución diferente del territorio. Sabíamos que el modelo de crecimiento industrial estaba agotado y era necesario buscar alternativas de base social y democrática antes de que el sistema diera una vuelta de tuerca más. El viejo Lefebvre nos había enseñado que cuando el régimen de acumulación entra en crisis busca, entre otras soluciones, modificar su dimensión espacial, pero no sabíamos cómo lo iba a hacer; realmente nadie lo sabía aunque se dibujaban bastantes opciones. Hoy lo tenemos muy claro, pero entonces sabíamos que la fórmula sería destructiva, que aumentaría las desigualdades, y que nuestra alternativa no tenía otra solución que buscar el camino que pudiera conducirnos a una sociedad de ciudadanos.

El método de trabajo se correspondía con esta filosofía. No podíamos tomar decisiones sin estudiar convenientemente la realidad municipal. De hecho no contratábamos la redacción de un documento de planeamiento sin haber realizado una extensa visita, haber entrevistado a los responsables municipales y a otros actores sociales y haber realizado un estudio previo nosotros mismos. Se hacían Pliegos de Condiciones a la medida, muy detallados y con hipótesis de trabajo explícitas, que dirigían desde el principio los esfuerzos de los equipos, muchos de los cuales eran jóvenes que se iniciaban en la disciplina. En esas condiciones se llegaron a contratar más de 40 documentos de planeamiento general. Pero este era sólo el trabajo de asistencia al planeamiento, porque el equipo tenía además la voluntad de crear un foro de debate disciplinar y una escuela de formación permanente de sus miembros. Estábamos buscando adelantar el futuro que se dibujaba incierto, explorando alternativas y tratando de desarrollar las dimensiones democráticas del gobierno de la ciudad y del territorio. Por entonces Javier había puesto en marcha un imaginativo y eficiente proceso de participación pública para el Plan Especial de Getafe, que se convirtió enseguida en una referencia profesional, pero queríamos ir más lejos. Era fundamental estudiar los ensayos que se estaban produciendo en todas partes. Organizamos varios encuentros con estudiosos de Gran Bretaña y de Italia donde se ensayaban nuevas modalidades de organización productiva y se desvelaba la importancia vital del entorno no capitalista del sistema, que cada vez más se perfilaba como nuestro objeto central. Llega un momento en que es difícil recordar qué era iniciativa de Javier y qué lo era de otros miembros del equipo pero no hay duda de que nada de aquello hubiera ocurrido bajo otra responsabilidad que no fuera la suya, porque su autoridad reconocida por otros actores externos, amparaba ampliamente todas las "extravagancias" que, en términos estrictamente funcionariales, se nos pudieran haber achacado. $Y$ él estaba encantado de ser el jefe de aquella banda, que los sábados por la mañana —uno de cada dos nos tocaba trabajar - hacía excursiones a los diferentes lugares y territorios de la provincia para que todos los miembros $-\mathrm{y}$ algunos que se apuntaban-, incluidos los abogados, aprendiéramos a entender cómo era el paisaje y el paisanaje con los que trabajábamos. Se hablaba de ecosistemas, de su evolución, de los poblamientos y su historia, y de su defensa frente a la avalancha inmobiliaria que ya se perfilaba como el lado oscuro del urbanismo madrileño. También se puso en marcha una editorial que en pocos meses dio a luz más de una docena de publicaciones sobre los temas más diversos: desde estudios sobre la renta urbana 
hasta arquitectura popular, pasando por ensayos sobre los nuevos modos productivos y las descripciones territoriales de la provincia, etc.

Fue poco más que un sueño. Las elecciones generales de octubre de 1982 dieron la primera mayoría al PSOE, y en cierto modo marcaron el final de esta experiencia. Con el gran buque insignia de COPLACO (Comisión de Planeamiento y Coordinación del Área Metropolitana) y todo su aparato burocrático, nuevos actores políticos decidieron que aquella frágil embarcación de Diputación ya no tenía razón de ser. Antes del verano de 1983 fuimos absorbidos en la nueva Consejería de Política Territorial — no recuerdo bien su nombre exacto- de la Comunidad de Madrid, cuyo ambiente sofocante, y cuyos objetivos tan alejados de nuestro proyecto apenas pudimos soportar más de veinte días, a pesar de que inicialmente recibí el encargo de dirigir el servicio de Planeamiento Provincial que nos devolvía en cierto modo el ámbito de nuestro trabajo. Javier ni siquiera hizo el recorrido y se refugió directamente en el IEAL, donde pudo desarrollar mejor su vocación de estudioso que tantos frutos ha proporcionado, aunque siguiera participando puntualmente en tareas de planeamiento y en la redacción de regulaciones urbanísticas.

Para mí este grupo de trabajo, la definición que hizo de sus objetivos y sus campos de intervención, así como sus logros, constituye una pequeña joya que da la medida del genio inconformista de Javier, de su capacidad para transformar los ambientes más tópicos en espacios de innovación y de creación cultural. Algo, por otra parte, que fue haciendo por donde quiera que pasó a lo largo de su vida. Fue también una oportunidad perdida que sucumbió ante la máquina inmobiliaria que exigía burocracias y políticas más afines, como las que proporcionó desde el principio la Consejería de Política Territorial. Para nosotros fue fundamental buscar el camino de la complejidad frente a la lógica simplista de los agregados monetarios y sus leyes mercantiles, y nos derribó precisamente la nueva hegemonía inmobiliario-financiera que iba a liderar el paso a la globalización de una región, que había perdido sus funciones de gran fábrica metropolitana. No fuimos las únicas víctimas. Las asociaciones de vecinos fueron absorbidas por los partidos políticos y con ellas se perdió un patrimonio social y una cultura democrática inapreciable junto con la oportunidad de trabajar por una ciudadanía plena. También los redactores del Plan de Madrid de 1985 vieron cómo nuevos personajes lanzaban duras campañas contra aquella planificación inspirada en la Austeridad que había puesto el énfasis en lo social y en la recuperación de la ciudad. Se la acusaba de ser un obstáculo para el desarrollo, un freno para el nuevo teatro de competitividad planetaria que se inauguraba entonces. Boyer desde la visión neoliberal y Castells como apóstol de la revolución tecnológica - por mencionar dos presuntos extremos, convictos, sin embargo, de coincidencia- se convierten en el azote de un Plan que les parece restrictivo y propugnan reavivar el crecimiento, cuando se derrumbaba la base industrial y se detenía el crecimiento demográfico. Supongo que para estos sabios tan sesudos la gente contaba poco y nosotros no hacíamos más que niñerías, pero aquellos polvos han traído estos lodos que tanto escándalo levantan ahora sin haber resuelto - más bien lo contrario- ninguno de los graves problemas que ha engendrado este despropósito urbanizador. Niños ojalá, jóvenes inconformistas desde luego, Javier tenía esa cualidad contagiosa que rejuvenecía lo que tocaba con su entusiasmo, su inteligencia y su inagotable energía. Fue un privilegio cabalgar junto a aquel grupo de amotinados con él a la cabeza. 